\title{
Indications for worldwide increased norovirus activity associated with emergence of a new variant of genotype II.4, late 2012
}

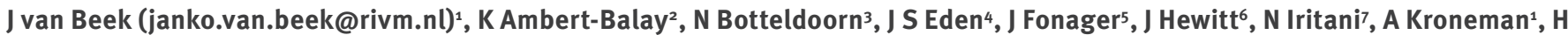
Vennema ${ }^{1}$, J Vinjé $e^{8}$, P A White $^{4}$, M Koopmans $^{1}$, on behalf of NoroNet ${ }^{9}$

1. National Institute for Public Health and the Environment, Bilthoven, The Netherlands

2. National Reference Centre for Enteric Viruses, Dijon, France

3. Scientific Institute of Public Health, Brussels, Belgium

4. University of New South Wales, Sydney, Australia

5. Statens Serum Institut, Copenhagen, Denmark

6. Institute of Environmental Science and Research, Porirua, New Zealand

7. Osaka City Institute of Public Health and Environmental Sciences, Osaka, Japan

8. Centers for Disease Control and Prevention, Atlanta, GA, United States

9. http://www.noronet.nl

Globally, surveillance systems showed an increase in norovirus activity in late 2012. Molecular data shared through the NoroNet network suggest that this increase is related to the emergence of a new norovirus genotype II.4 variant, termed Sydney 2012. Healthcare institutions are advised to be prepared for a severe norovirus season.

In the United Kingdom (UK), the Netherlands, and Japan, norovirus (NoV) epidemiological and laboratory surveillance systems show increased levels of NoV activity compared to previous seasons, in late 2012 [1-3]. Similarly, increases have been noted in Australia, France and New Zealand (unpublished data). At this stage, and with the limited surveillance of NoV in most countries, it is difficult to conclude if these increases denote early seasonal activity or truly increased incidence, although for the UK the latter has been suggested. On 29 November, and on 4 and 6 December, ProMed (http://www.promedmail.org/) messages reported a dramatic rise in NoV hospital outbreaks in England, a $64 \%$ higher number of confirmed NoV laboratory reports (hospital- and community-acquired) in England and Wales, and NoV-related deaths in elderly in Japan. The first molecular data uploaded to the international molecular surveillance database NoroNet from Australia, France, New Zealand and Japan indicate that this increase is associated with emergence of a new variant of genotype II.4 (GII.4). The first report of this variant was from Australia in March 2012 (personal communication P.A. White, September 2012), and the strain sequence was submitted to GenBank (accession number: JX459908.1). In the United States (US), the variant (named Sydney 2012) was detected in September 2012 in five of 22 (23\%) laboratory-confirmed outbreaks, and in November in 37 of 71 (52\%) laboratory-confirmed outbreaks (recorded in the US norovirus surveillance network CaliciNet) [4]. In two European countries that have not reported any indications of increased activity, the new variant has been found in outbreaks, two in Belgium (September and December 2012) and one in Denmark (November 2012). Other countries participating in NoroNet have not yet reported the new variant.

NoV is the predominant aetiological viral agent of acute gastroenteritis worldwide and is present throughout the year, but most prevalent in the winter season in temperate climates. In the last decade, strains belonging to NoV GIl.4 have been responsible for the majority of outbreaks, as well as community cases of acute gastroenteritis. It has been suggested that hospitalisation and deaths occur more frequently during peak seasons associated with new NoV GIl.4 variants [5-7]. Since 1995, new epidemic variants of GIl.4 have emerged every two to three years, with population immunity and genetic drift as major evolutionary driving forces [8]. Emergence of new variants has been associated with increased NoV activity early in the season [9-11]. The newly found NoV GIl.4 Sydney 2012 variant has evolved from previous NoV GII.4 variants (Figure 1) and will be described in detail elsewhere. Briefly, the NoV GIl.4 Sydney 2012 variant has a common ancestor with the dominant NoV GII.4 variants Apeldoorn_2007 and NewOrleans_2009, but is phylogenetically distinct. Amino acid changes are seen in the main epitopes located at the $\mathrm{P}_{\mathbf{2}}$ domain, consistent with observations from prior epidemics. This may have led to an escape to 
FIGURE

Neighbour-joining tree of norovirus GII.4 capsid amino acid sequences

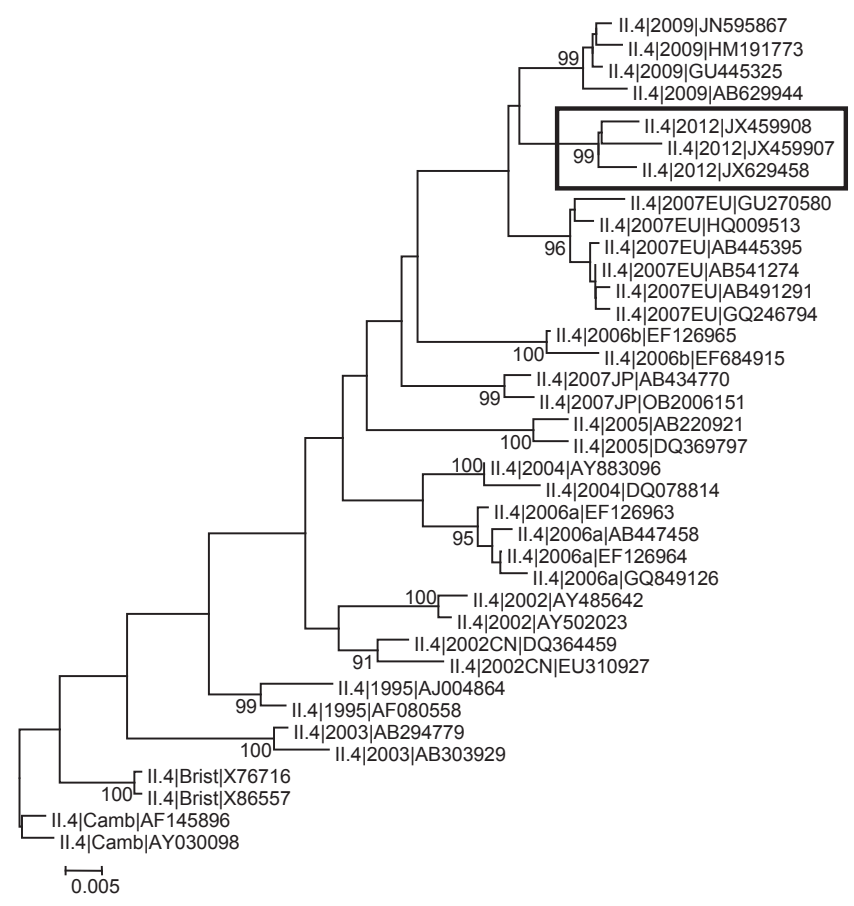

Representative strains from the variant typing tool were used in this analysis. The taxa are named with genotype|variant name|accession number. Taxa representing the recent NoV GII.4 Sydney 2012 variant are boxed. The bootstrap values in percentage of 500 replicates are shown next to the major branches. The evolutionary distances were computed using the Poisson correction method in the units of the number of amino acid substitutions per site with the exclusion of gaps leaving a total of 536 positions in the final dataset. Phylogenetic analyses were conducted in MEGA4 [12].

existing herd immunity and might explain the observed increased outbreak activity.

The reference set of the Norovirus Typing Tool has been updated to correctly assign GII.4 Sydney 2012 sequences. This web-based tool (http://www.rivm.nl/ $\mathrm{mpf} /$ norovirus/typingtool) is publicly available for genotyping of NoV sequences and was developed to facilitate standardisation of nomenclature [13].

\section{Conclusion}

Various countries around the globe have reported a higher incidence of NoV outbreaks or illness late 2012, and the first molecular data available via NoroNet suggests that this increase is related to emergence of a new variant of NoV GII.4. More data is needed to confirm the association between a higher NoV incidence and the new NoV GII.4 2012 variant. For this, we invite new members to join the NoroNet network (http://www. noronet.nl). Noronet is a worldwide network for NoV molecular and epidemiological surveillance, through which countries in Europe, Asia, and Australasia have shared NoV outbreak data, sequences, and other information. The NoroNet database, including analysis tools, is accessible for all NoroNet members.

With the early signs of a severe NoV season, healthcare institutions are advised to be prepared for NoV introductions. Outbreak management measures, like stringent hygiene measures and quarantine of infected cases, can help to reduce the size of outbreaks $[14,15]$.

\section{References}

1. Rijksinstituut voor Volksgezondheid en Milieu (RIVM). Virologische weekstaten. Bilthoven: RIVM. [Accessed 13 Dec 2012]. Dutch. Available from: http://www.rivm.nl/ Onderwerpen/Onderwerpen/V/Virologische_weekstaten

2. Health Protection Agency (HPA). Update on seasonal norovirus activity. London: HPA, 18 December 2012. Available from: http://www.hpa.org.uk/webw/HPAweb\&HPAwebStandard/ HPAweb_C/1317137436431

3. National Institute of Infectious Diseases (NIID). Flash report of norovirus in Japan. Tokyo: NIID. [Accessed 13 Dec 2012]. Available from: http://www.nih.go.jp/niid/en/iasr-noro-e.html

4. Vega E, Barclay L, Gregoricus N, Williams K, Lee D, Vinjé J. Novel surveillance network for norovirus gastroenteritis outbreaks, United States. Emerg Infect Dis. 2011;17(8):1389-95.

5. Desai R, Hembree CD, Handel A, Matthews JE, Dickey BW, McDonald S, et al. Severe outcomes are associated with genogroup 2 genotype 4 norovirus outbreaks: a systematic literature review. Clin Infect Dis. 2012;55(2):189-93.

6. van Asten L, Siebenga J, van den Wijngaard C, Verheij R, van Vliet $\mathrm{H}$, Kretzschmar M, et al. Unspecified gastroenteritis illness and deaths in the elderly associated with norovirus epidemics. Epidemiology. 2011;22(3):336-43.

7. Harris JP, Edmunds WJ, Pebody R, Brown DW, Lopman BA. Deaths from norovirus among the elderly, England and Wales. Emerg Infect Dis. 2008;14(10):1546-52.

8. Siebenga JJ, Vennema H, Renckens B, de Bruin E, van der Veer $B$, Siezen RJ, et al. Epochal evolution of GGII.4 norovirus capsid proteins from 1995 to 2006. J Virol. 2007;81(18):9932-41.

9. Siebenga J, Kroneman A, Vennema H, Duizer E, Koopmans M. Food-borne viruses in Europe network report: the norovirus GII.4 $2006 \mathrm{~b}$ (for US named Minerva-like, for Japan Kobe034-like, for UK V6) variant now dominant in early seasonal surveillance. Euro Surveill. 2008;13(2):pii=8009. Available from: http://www.eurosurveillance.org/ViewArticle. aspx?Articleld $=8009$

10. Kroneman A, Vennema H, van Duijnhoven $\mathrm{Y}$, Duizer $E$, Koopmans $M$. High number of norovirus outbreaks associated with a GGII.4 variant in the Netherlands and elsewhere: does this herald a worldwide increase? Euro Surveill. 2004;8(52):pii=2606. Available from: http://www. eurosurveillance.org/ViewArticle.aspx?Articleld=2606

11. Kroneman A, Vennema H, Harris J, Reuter G, von Bonsdorff $\mathrm{CH}$, Hedlund $\mathrm{KO}$, et al. Increase in norovirus activity reported in Europe. Euro Surveill. 2006;11(50):pii=3093. Available from: http://www.eurosurveillance.org/ViewArticle. aspx?Articleld $=3093$

12. Tamura K, Dudley J, Nei M, Kumar S. MEGA4: Molecular Evolutionary Genetics Analysis (MEGA) software version 4.0. Mol Biol Evol. 2007;24(8):1596-9.

13. Kroneman A, Vennema H, Deforche K, v d Avoort H, Penaranda $S$, Oberste MS, et al. An automated genotyping tool for enteroviruses and noroviruses. J Clin Virol. 2011;51(2):121-5.

14. Division of Viral Diseases, National Center for Immunization and Respiratory Diseases, Centers for Disease Control and Prevention. Updated norovirus outbreak management and disease prevention guidelines. MMWR Recomm Rep. 2011;60(RR-3):1-18.

15. Friesema IH, Vennema H, Heijne JC, de Jager CM, Morroy G, van den Kerkhof JH, et al. Norovirus outbreaks in nursing homes: the evaluation of infection control measures. Epidemiol Infect. 2009;137(12):1722-33. 